\title{
La franja fronteriza Chiapas-Guatemala. Notas de campo
}

\section{The Chiapas-Guatemala border strip. Field notes}

\author{
Dolores Camacho Velázquez \\ (D) https://orcid.org/0000-0001-8275-8285 \\ Universidad Nacional Autónoma de México, \\ Centro de Investigaciones Multidisciplinarias sobre Chiapas y la Frontera Sur, \\ doloresc@unam.mx
}

\section{Resumen:}

Se ofrece una narrativa sintética sobre avances de un proyecto de investigación que tiene como objetivo «ldentificar, describir y reflexionar de manera colectiva sobre la complejidad que encierran las dinámicas sociales en la franja fronteriza Chiapas-Guatemala». Se adelantan resultados sobre los recorridos de campo efectuados y que tuvieron la pretensión de identificar algunos de los elementos que definen la vida en la frontera desde la perspectiva de quienes la habitan $y$, por supuesto, de sus interlocutores, en este caso un grupo de investigadores que llegamos a su territorio a preguntarles qué piensan sobre su vida en lo que llamamos la franja fronteriza de Chiapas-Guatemala. Se toma como contexto lo que se sabe de la frontera a través de libros y medios de comunicación, así como la discusión generada en los seminarios sobre el concepto de frontera.

Palabras clave: fronteras, Centroamérica, narrativas, cultura.

\section{Abstract:}

A brief narrative about advances in a research project that aims to identify, describe and reflect collectively on the complexity of social dynamics in the Chiapas-Guatemala border strip is offered. Results are advanced on the field trips carried out and that were intended to identify some elements that define life on the border, from the perspective of those who inhabit it and of course from their interlocutors, in this case a group of researchers who arrived at their territory to ask them what they think about their life in what we call the border strip of Chiapas-Guatemala, the narrative offered here is reflected taking as context what is known about the border through books and media, as well as the discussion generated in the seminars on the concept of border. 


\section{Introducción}

nvestigadores y estudiantes integramos un grupo de trabajo en torno al proyecto IN303217 «La frontera Chiapas-Guatemala: territorio, problemáticas y dinámicas sociales», financiado por el Programa de Apoyo a Proyectos de Investigación e Innovación Tecnológica (PAPIIT), en 2017, con el objetivo de «Identificar, describir y reflexionar de manera colectiva sobre la complejidad que suponen las dinámicas sociales en la franja fronteriza Chiapas-Guatemala». Incluye actividades como: seminarios de discusión, reuniones de trabajo, registros etnográficos y cursos de actualización. Se pretende aportar al conocimiento de esta franja fronteriza elementos para identificar las problemáticas que experimentan cotidianamente sus habitantes y las formas que tienen de vivir la frontera, además de abonar al estudio del territorio fronterizo.

En el grupo participan o han participado académicos de distintas disciplinas de la UNAM: Celia Ruiz de Oña, Antonio Castellanos, Sandra Cañas, Enriqueta Lerma, Amanda Úrsula Torres, además de Arturo Lomelí González, investigador de la Universidad Autónoma de Chiapas, Rosario Hernández, estudiante de doctorado del posgrado en Antropología de la UNAM y Adriela Pérez, de la maestría del mismo posgrado. En el segundo periodo del proyecto se sumaron dos estudiantes de historia y dos de sociología, becados para la conclusión de sus estudios de licenciatura. Además, han participado investigadores externos como invitados en eventos y seminarios desarrollados en el CIMSUR.

Este escrito tiene la finalidad de compartir las primeras reflexiones surgidas de los recorridos de campo durante dos años. Se ofrece una descripción de lo observado y analizado a la luz de la bibliografía revisada. El texto se organiza en función de ello. Por lo tanto, inicia con una descripción sintética del proceso de investigación y de la conformación del grupo. En una segunda parte se describe el primer recorrido de campo y se insertan algunas reflexiones. Y una tercera etapa en la que se da seguimiento al segundo recorrido. Finalmente, se presentan algunos comentarios de cierre.

\section{El inicio: acercamiento metodológico}

En el primer año sostuvimos reuniones diarias durante dos semanas y construimos colectivamente las actividades del ciclo. Elegimos la bibliografía a revisar y 
acordamos un calendario de sesiones de un seminario permanente para discutir en grupo los textos elegidos sobre la frontera sur y sobre el concepto de frontera. En ese marco organizamos el Encuentro Pueblos y Fronteras, en mayo de 2017, con la concurrencia y participación de especialistas en temas de las fronteras norte y sur del país. Pudimos conocer de ese modo cómo se están visualizando los estudios desde el norte y cómo miran desde ahí la frontera sur, así como las perspectivas de análisis que están utilizando. En el intercambio de opiniones y experiencias se concluyó de manera general que las fronteras nacionales tienen que estudiarse de manera integral, para lo cual es necesario conocerlas y pensarlas.

Los participantes en el proyecto acordamos el propósito, entonces, de conocer el territorio fronterizo de manera colectiva, con base en registros etnográficos y la comparación de sus distintas áreas, desde una perspectiva multidisciplinaria. De ese modo, uno de los primeros problemas que enfrentamos fue identificar la metodología para realizar el trabajo de campo y para analizar los resultados. Teníamos claro que sería difícil hacer etnografía dada la amplitud territorial y temática que pretendíamos abarcar; en ese sentido, debíamos encontrar la ruta para obtener la información que nos permitiera satisfacer las expectativas de cada uno de los participantes, y fue uno de los temas de mayor discusión en el grupo. Para resolverlo, antes de realizar el primer recorrido de campo dedicamos dos semanas del mes de junio a un debate intenso; revisamos bibliografía básica sobre estudios regionales, estudios etnográficos y experiencias de grupos de investigación, en el afán de llegar a un acuerdo mínimo (Contreras, 1998; Fábregas et al., 1985; 2015; Centro de Estudios Indígenas, 1987).

Tomando en cuenta nuestros intereses y experiencias individuales y el objetivo del proyecto emprendimos un primer recorrido de 15 días por la franja fronteriza, con el propósito de practicar un acercamiento a nuestro objeto de estudio de manera colectiva y en un mismo momento; la idea era conocer y definir paisajes, hablar con la gente y preguntar sobre su vida diaria. Siguiendo los manuales de observación y teniendo como referencia los conocimientos previos pudimos mantener una guía mínima; algunos del grupo tenían referencias de ciertas partes de la región y otros desconocían prácticamente todo el territorio. Cada uno llevaba sus propios intereses temáticos y una idea de la frontera, así como de sus problemas y de cómo transcurre ahí la vida cotidiana. Se optó por realizar juntos el recorrido, hablar con las mismas personas y transitar los mismos caminos, y realizar reuniones para construir nuestra interpretación de lo observado y escuchado. Lo que nos guió, tanto en el periplo como las reflexiones, fue identificar 
las singularidades y los problemas percibidos por los habitantes. Para ello observamos, entrevistamos y tomamos registro en notas de campo y grabaciones. Cabe aquí mencionar un elemento que surgió al calor de estas reflexiones: la diferencia entre lo que habíamos escuchado en medios de comunicación o lo leído en la bibliografía revisada sobre el tema y lo que referían los habitantes.

\section{Primer recorrido}

Salimos el 26 de julio de 2017 de San Cristóbal de Las Casas y llegamos por la noche a Tapachula. El trayecto fue de 2300 kilómetros, visitando municipios en condición de frontera y diversos pasos fronterizos entre Chiapas y Guatemala. El punto de llegada fue El Ceibo, ubicado en Tenosique, Tabasco, y desde ahí tomamos por Palenque y, finalmente, el 9 de agosto, volvimos a San Cristóbal de Las Casas, Chiapas. ${ }^{1}$

De Tapachula pasamos por el principal puerto de Chiapas, Puerto Chiapas, que tiene bodegas para la pesca y cuenta con una instalación de desembarque de turistas que llegan en cruceros a visitar las fincas y para embarcar y descargar mercancías nacionales e internacionales. A pesar de ser un espacio transitado, las personas que ahí habitan tienen poca idea de que viven en una frontera. Posteriormente visitamos Ciudad Hidalgo, que colinda del lado guatemalteco con Tecun Umán. El trazo de esta franja fronteriza lo marca la corriente del río Suchiate. En este paso hay dos vías para cruzar la frontera: la formal, a través de las oficinas del Sistema de Administración Tributaria (SAT) y de Migración, por lo que debe cumplirse con los requisitos de ambos lados: para el caso de mexicanos, presentar pasaporte o credencial de elector y hacer el pago mínimo en el torniquete, el paso puede hacerse a pie o en cuatrimoto y la vigilancia es visible. Pero también está la vía informal: «el coyote» se ubica apenas abajo del puente formal, y el viaje se realiza en balsas hechizas con cámaras de llanta y madera. Es notorio el nivel de organización que tienen quienes controlan las balsas. Por esta vía transitan tanto personas como mercancías de todo tipo; y aunque esta acción es observada por autoridades, no hay ningún control sobre el cruce; la inseguridad es evidente; aquí se distribuyen todo tipo de mercancías, incluyendo drogas. La gente cercana a estos lugares considera que la violencia y la participación de

1 El recorrido quedó registrado gracias a Félix Lerma, quien fue invitado a acompañarnos y aplicó el GPS en todo el tramo. 
grupos criminales en estas actividades es común, y como una señora comentó: "ahora sí, sabemos lo que es vivir en frontera», haciendo referencia a la inseguridad, que en los últimos tiempos se ha incrementado.

La siguiente visita fue a Talismán, municipio de Tuxtla Chico que colinda con la población guatemalteca de El Carmen, Malacatán-Guatemala. En este cruce parece haber poca actividad; aunque existe aduana y migración formal, es poco visible el paso de personas; hay flujo de mercancías, en especial autos viejos que van hacia Guatemala; aquí no es perceptible la inseguridad.

Visitamos después algunos lugares de la región que no son propiamente pasos fronterizos, pero donde es clara la existencia de la frontera. En la carretera de Tapachula a Huixtla se encuentra el mayor control de migración. A partir de ahí ya no pueden pasar los centroamericanos, salvo que cuenten con permisos para hacerlo. En Huixtla existe un ingenio azucarero conocido por la gran cantidad de mano de obra guatemalteca que ahí labora. Hasta este lugar suelen llegar con permisos para trabajar personas que van y vienen y que, por lo tanto, no tienen problemas migratorios.

En la zona de Unión Juárez se ubica el volcán Tacaná, que divide Chiapas de Guatemala (San Marcos). Zona turística y productora de café, es tierra de grandes fincas con importante colonización alemana, algunas de las cuales se han convertido en hoteles; es perceptible la estrecha relación entre la gente local con migrantes guatemaltecos que viven en las faldas del volcán y que llegan a este municipio a trabajar y también a vender sus productos agrícolas; caminan por el Tacaná no por los pasos fronterizos reconocidos como tales; la gente que habita estas zonas no ve como problema esta migración constante, dado que hay importantes relaciones entre la población de ambos lados de la frontera, sobre todo entre familiares y familias divididas, ya sea porque al marcarse la frontera quedaron unos de un lado y otros del otro o porque se casaron y se quedaron a vivir en México o en Guatemala, por lo que la idea de frontera como separación solo la tienen cuando hacen referencia a los grupos criminales que existen en ambos lados, especialmente en los pasos fronterizos (legales o ilegales).

Así concluimos esta primera parte del recorrido. De manera general pudimos percatarnos de que existe inseguridad. Las recomendaciones de los lugareños fueron no viajar de noche, no relacionarse con los grupos que trabajan en «los pasos fronterizos», andar en grupo y ser cuidadosos con los comentarios en público. En los hoteles y restaurantes evitamos comentar lo observado, sobre todo en la ciudad de Tapachula, lugar donde pernoctamos al cabo de cada recorrido. 
Los hoteles manejan sistemas de seguridad. No dan información sobre los huéspedes debido a los casos de extorsión que se han registrado. También pudimos observar que las revisiones de migración se han adentrado hacia México, y se ha dejado más amplia la zona libre donde los migrantes andan sin problemas por las ciudades fronterizas.

La segunda parte del recorrido inició en Motozintla, Chiapas, lugar considerado como de gran importancia en las relaciones comerciales México-Guatemala. Este municipio y El Porvenir, ubicados en la misma ruta, fueron afectados por el huracán Stan, por lo que su importancia económica ha disminuido; sin embargo, existe una relación histórica con Guatemala; hay innumerables pasos informales por donde existe todavía conexión entre habitantes de ambos lados. La gente que habita en estos lugares los considera peligrosos debido a que no cuentan con vigilancia y que por ahí atraviesan todo tipo de personas y mercancías. La inseguridad es perceptible. La gente opina que esta se ha incrementado. Hacen referencia explícita a los migrantes. Para pernoctar en esta zona elegimos Frontera Comalapa, lugar de gran actividad comercial muy cercano a La Mesilla, que es el paso fronterizo más importante de la zona. Aquí se concentra la actividad comercial de la región. Los habitantes recuerdan que el nombre de Frontera Comalapa se debe justamente a que ahí iniciaba la frontera, y con el acuerdo de límites esta se hizo adentro de Guatemala, por lo que quedó en una comunidad del mismo municipio; en este paso fronterizo hay gran actividad comercial, oficinas de migración y SAT; por lo tanto, hay cruce legal de mercancías, pero apenas unos metros abajo hay vías por las que se puede ir y venir si ningún control; la gente de estos lugares comenta que prefieren los pasos no formales porque es más fácil y seguro para ellos.

Sobre los municipios de Frontera Comalapa y Chicomuselo hay distintos tipos de pasos, desde aquellos sin ningún control hasta los que tienen algunos controles aplicados por los habitantes de los ejidos, quienes hacen las veces de migración o SAT. Uno de ellos es el del ejido Sabinalito, en Frontera Comalapa, que colinda con comunidades de Huehuetenango. Se utiliza ahí un lazo como sistema de control. Pasan por ahí sin restricciones vehículos con personas y camiones con mercancía, aunque estos últimos deben pagar una cuota, dependiendo del tipo y la cantidad de su carga. Hay productos que tienen prohibida la entrada o la salida. Uno de los principales que entran por ahí a Guatemala es el maíz producido en la región fronteriza; ${ }^{2}$ y se introduce azúcar de Guatemala a México. El

\footnotetext{
2 Los habitantes de esta región no permiten el paso de maíz de otras regiones de Chiapas porque se abarata el precio de venta en Guatemala.
} 
comercio es intenso incluso por la noche. En medio del camino hay bodegas en las que se carga y descarga la mercancía.

Otro paso informal está en el ejido Cristóbal Colón, en La Trinitaria. Abarca una gran franja en la que colindan ríos y tierras de trabajo, solo siguiendo las lagunas de Colón (centro ecoturístico). Se aprecia un flujo intenso de personas que cruzan por esa vía a territorio mexicano con la intención de vender sus productos o trabajar en tierras de ejidatarios mexicanos. Algunos se quedan por semanas viviendo en chozas en esos terrenos y otros van y vienen diario. Hay caminos que comunican diversos poblados de uno y otro lado sin ninguna vigilancia; sin embargo, si se adentran hacia Comitán se topan con sistemas de detección de migrantes. Pero, al igual que en otros territorios, hay un espacio por el que transitan sin ser molestados.

Siguiendo por la carretera fronteriza se llega a Carmen Xhan-Gracias a Dios; es un paso formal en el que existe oficina de migración, pero no del SAT. Por ahí los coches con placas chiapanecas cruzan con permiso de migración por tres días, pero sin autorización legal del SAT. Aquí también hay intenso intercambio de mercancías por la entrada hacia Guatemala; siempre pueden verse tráileres cargados de mercancías, que van o vienen hacia México.

El paso Tziscao-Quetzal, con alta afluencia turística, se ubica en el lago Tziscao. Es un cruce sin control para el paso de mercancías y personas. Aquí hay conflictos entre las poblaciones de ambos lados de la frontera, porque se disputan a los turistas para la venta de artesanías. En ambos lados hay un pequeño mercado de artesanías y comida. En los últimos años se ha incrementado la infraestructura turística del lado mexicano, con lo cual el contraste con la sencillez del lado guatemalteco es más evidente.

Avanzando sobre la carretera fronteriza nos adentramos en territorios que se diferencian de los anteriores por la forma en que fueron poblados, en respuesta a un proyecto de colonización de terrenos de la Selva. Los habitantes provienen, en general, de municipios de los Altos de Chiapas, de diversos estados del país y otros de Guatemala que vinieron huyendo de la guerra de los años ochenta y fueron nacionalizados mexicanos. Por ello estas poblaciones tienen características culturales heterogéneas dentro de un mismo ejido o municipio.

En el recorrido fue posible apreciar el contexto territorial de Nuevo San Juan Chamula y Nuevo Huixtán (municipio de Las Margaritas), poblaciones asentadas durante la década de 1960, producto de la colonización de la Selva y de la continuación del reparto agrario para indígenas sin tierras de los Altos de Chiapas. 
Maravilla Tenejapa es un municipio que también tiene estas características. A simple vista se aprecia cómo en sus espacios urbanos reproducen muchas de los rasgos de los municipios de donde son originarios la mayor parte de los habitantes, al igual que en el nombre mismo del poblado. Se hablan diversas lenguas de origen maya, tanto chiapaneco como guatemalteco.

El siguiente punto del recorrido fue Benemérito de las Américas, ubicado en Marqués de Comillas. Es también un municipio emblemático de la zona. Lo habitan sobre todo colonizadores que llegaron de otros estados, pero tiene una historia de relaciones continuas con la población guatemalteca. Los moradores de esta región cuentan con una identidad regional construida recientemente, por lo que aún es posible ubicar las diferencias de origen de sus habitantes. En estos territorios existen muchas vías de comunicación y prácticamente no hay controles de migración. En la zona de Marqués de Comillas se ubican proyectos ecoturísticos, de conservación de la Selva Lacandona y también se ha expandido el cultivo de palma africana. Esto último ha propiciado recientemente la creación de plantas procesadoras. El paisaje ha cambiado a raíz de ello. Muchos terrenos están sembrados de palma y a lo largo de la carretera fronteriza se observan muchos anuncios sobre proyectos ecoturísticos y de conservación. Visitamos el paso de Nuevo Orizaba-Ingenieros, donde existe una gran construcción que pretende ser el centro de control mexicano. Hay vigilancia militar pero no oficinas de migración ni del SAT, y un intenso flujo de mercancías y personas que se mueven utilizando el trasporte terrestre que funciona hasta la línea fronteriza de ambos países.

Otro paso visitado fue el de Frontera Corozal. Luego de un recorrido en lancha sobre el Usumacinta, saliendo de Escudo-Jaguar hacia la localidad de Bethel, en Guatemala, el río marca una línea divisoria. Se observa una intensa comunicación y relaciones comerciales frecuentes entre poblaciones de la frontera por medio de lanchas, que funcionan como medio de transporte colectivo; otras hacen viajes privados, ya sea para transportar turistas o mercancías de mayor tamaño. Los habitantes de esta región mantienen estrechas relaciones; de lado mexicano se venden productos industriales a los guatemaltecos y estos traen productos comestibles; por las mañanas Ilegan trabajadores de Guatemala a Frontera Corozal y al cumplir su turno regresan, por la tarde, a sus lugares de origen.

El recorrido concluyó con la visita a El Ceibo, del estado de Tabasco. Era importante llegar hasta este lugar puesto que es un paso oficial con oficinas del SAT y de migración. Es la ruta migratoria y comercial de los municipios de Palenque, La 
Libertad, Catazajá y Reforma, Chiapas, y es considerada una de las más peligrosas para los migrantes. Ahí conviven lo legal con lo ilegal en todos los sentidos.

\section{Segundo recorrido}

En el segundo recorrido, en junio de 2018, se planteaba profundizar en algunos de los aspectos más importantes identificados en el primero: más que visitar pasos fronterizos, realizamos entrevistas a actores sociales de cada zona. Discutimos antes algunos aspectos concernientes a la metodología a seguir para esta etapa, tanto para la recopilación de datos como para su análisis. Decidimos adoptar un método etnográfico basado en las narrativas como el procedimiento más claro para obtener y analizar la información de acuerdo con los objetivos del proyecto y con la formación de los participantes. Autores como Geertz (2003), Jimeno (2016) y Visacovsky (2016), entre otros, fueron básicos para la discusión. Esa perspectiva se sintetiza en la siguiente transcripción:

En la medida en que la narrativa está construida por sujetos o grupos sociales según sus sistemas de significación y sus experiencias históricas concretas, se abren las posibilidades para una comprensión desde fuera. La condición es que se evite la ilusión naturalista del relato y que se pueda acceder a su entramado de significación. Es decir, siempre y cuando se aboque el esfuerzo por desentrañar las condiciones particulares de creación y uso social en el contexto etnográfico, con la conciencia de que se realiza una traducción delicada y de que no se trata de revelar la «verdad» del relato ni que este consigne «la realidad» (Jimeno, 2016:14).

Con la metodología precisada analizamos los resultados del primer recorrido y continuamos con la revisión bibliográfica y hemerográfica sobre las zonas a visitar. Acordamos el tipo de información que buscaríamos. Las entrevistas se hicieron con la participación de los estudiantes que se integraron en este segundo año de trabajo.

Modificamos el orden del recorrido. Iniciamos en Frontera Comalapa. Ahí entrevistamos a profesores, pequeños productores de café, comerciantes y trabajadores, todos habitantes de la franja fronteriza. Los estudiantes integrados en el equipo, originarios de esta zona, participaron en las sesiones de discusión metodológica y nos guiaron para llegar con informantes primero de Pacayal, municipio de Amatenango de la Frontera, y posteriormente de Guadalupe Victoria. 
En La Providencia, localidad del Pacayal, entrevistamos al señor Lucio, un hombre mayor que vive solo. Su familia radica en la cabecera de Pacayal. Su propiedad, que es privada y produce café, colinda con Guatemala justo sobre la frontera de La Mesilla. Le preguntamos sobre su vida en la frontera. Afirmó que vive bien. Tiene claro que del otro lado de su propiedad es Guatemala, pero eso no le implica problemas; para él la limitación la hacen los terrenos privados de ambos lados y no la frontera nacional. Considera muy buena la convivencia con los guatemaltecos, sin ningún problema. Sus trabajadores son de ese origen. Opina que ellos trabajan más que los mexicanos y él les paga un poco mejor porque son buenos en lo que hacen; además, les ofrece un lugar donde dormir y comida.

En Pacayal Centro entrevistamos primero a la señora Otilia Barrios, quien vende pollos y es ama de casa; ella va a Guatemala por cuestiones religiosas, es evangélica, y no tiene clara la percepción de la frontera. Pero al platicar con ella e indagar en más detalles de su vida, dijo que su esposo sí tiene mucha relación con Guatemala porque trabaja para una empresa distribuidora de café y cuando se acaba la producción del lado mexicano él va a Guatemala a comprarlo; confiesa sentir peligro cuando pasa la frontera y lleva dinero, y que prefiere que le entreguen el producto en las cercanías y que vengan a cobrar a México. La frontera formal no tiene importancia para ellos, puesto que usan los pasos informales no solo para adentrarse en Guatemala sino para llevar o traer el café. La inseguridad le preocupa, pero afirma que es igual que en otras partes del país o de Guatemala, es decir, que vivir en la frontera no hace la vida más peligrosa.

Posteriormente interrogamos al profesor Lennin, quien conoce la historia del lugar y tiene su versión sobre la relación con Guatemala; sabe que sus antepasados vienen de ese país; asegura que el lugar que ahora ocupa su pueblo era Guatemala pero que cuando se hizo la frontera quedaron de este lado, porque «la frontera era en Frontera Comalapa». Sobre su vida, cuenta que sus antepasados llegaron hasta esta parte huyendo de las guerras de Guatemala y se quedaron sin saber que estaban en suelos mexicanos, pero también recuerda que en la época de Rufino Barrios, ${ }^{3}$ muchos guatemaltecos vinieron huyendo de la represión y se quedaron de este lado, "así que hay varias formas de haberse quedado como mexicanos» —aseguró.

Al explicar su visión de comunidad entre las poblaciones fronterizas afirmó que no hay problemas entre ellos, que muchos guatemaltecos de reciente llegada

3 Presidente de Guatemala entre 1873-1885, señalado por su feroz ataque a los pueblos indígenas. 
al lugar se quedan a vivir en el pueblo, algunos se casan y empiezan a adquirir derechos, y de igual manera algunos jóvenes se van para Guatemala porque se casan y se quedan allá, "así que hay una relación buena entre poblaciones de ambos lados de la frontera».

Guadalupe Victoria se localiza a una hora de Frontera Comalapa, en la parte alta fronteriza con Guatemala. En este pueblo mucha gente del lugar aún habla el jacalteco (poptí), pero «los jóvenes no [...] por vergüenza, ya no quieren reconocer que son indígenas pero su ascendencia es claramente poptí, están perdiendo su identidad». Así lo expresó el señor Baltazar Silvestre, uno de los defensores de la lengua. Comentó la relación cercana que tienen con el pueblo de Jacaltenango, Huehuetenango, Guatemala, de donde asegura son originarios muchos de los que habitan el lugar: «tienen los mismos apellidos y la misma lengua», y en los últimos años han intentado buscar sus relaciones con sus antepasados para entender lo que ocurrió y por qué se separaron.

En la actualidad este esfuerzo lo están haciendo con amigos y conocidos de Guatemala, por medio de la Academia de la Lengua de Jacaltenango, que han llegado a Guadalupe Victoria a buscar sus orígenes, pero no tienen avances porque muchos mexicanos no quieren reconocer ese pasado. Los habitantes de Pacayal les Ilaman «chahuiles», justo por su descendencia indígena. Recuerda que hubo otra causa que los hizo acercarse más a los pueblos guatemaltecos: la guerrilla guatemalteca. "Aquí se instaló un campamento, y eso hizo que se acercaran entre familias de ambos lados; los habitantes del campamento fueron reubicados en Campeche, donde viven actualmente, ya como mexicanos, y siguen hablando la lengua poptí, eso creó muchas relaciones con nosotros».

Después de conversar con varias personas de estos lugares y preguntarles sobre su percepción de la vida en la frontera, supimos que la gente tiene una clara idea de su cercanía con Guatemala. Muchos migrantes pasan constantemente por su territorio, lo cual es normal en su vida y solo se sienten amenazados por aquellos que se dedican a actividades ilícitas relacionadas con el tráfico de drogas y la prostitución, pero en esos grupos hay mexicanos y extranjeros. Ven la frontera como un lugar de intercambio comercial y los pueblos de Guatemala como puntos cercanos con gran comunicación, a donde van a comprar mercancías si es necesario y también de paseo, a visitar amigos o parientes. En los últimos años, coinciden los entrevistados, los mexicanos ya no van de compras a Guatemala por el tipo de cambio; la devaluación de la moneda mexicana ha encarecido todos los productos guatemaltecos y, por lo tanto, ya no les conviene 
el intercambio. Nos aseguran que antes compraban insecticidas y fertilizantes del otro lado, «pero ahora eso ya no es costeable».

El recorrido continuó hacia la parte de la Selva Lacandona. El paisaje cambia, tanto el natural, siguiendo los ríos Usumacinta y Lacantún, como el cultural con poblaciones de múltiples regiones del país y del mismo estado de Chiapas. Tomando la carretera fronteriza llegamos a Nuevo San Juan Chamula, municipio de La Trinitaria, donde entrevistamos al presidente del comisariado ejidal. Este poblado está compuesto por chamulas que fueron reubicados en estas tierras como una forma de colonizar el lugar y para resolver un problema de demanda de tierras de los Altos de Chiapas. El pueblo queda a cinco kilómetros de la frontera guatemalteca. El presidente del comisariado ejidal nos habla de muy buenas relaciones entre las naciones vecinas, incluso de guatemaltecos que se quedaron de este lado en la época de la guerra y fueron considerados con derechos para tener tierras y que ahora están integrados, aunque siguen hablando sus lenguas originarias. Se casan entre ellos sin importar sus orígenes, pero mantienen a la vez las relaciones con sus respectivos lugares de origen: Chamula y Guatemala. Refirió que «recientemente han llegado personas de pueblos de Guatemala a vivir en el poblado, porque se casan, cuando un joven de Guatemala se casa con una mujer del lugar puede adquirir derechos sobre la tierra», y no hay conflictos.

Boca Chajul, siguiente poblado en nuestro trayecto, se encuentra aproximadamente a $10 \mathrm{~km}$ de la frontera con Guatemala. Felipe, habitante del lugar, reflexiona ante las preguntas relacionadas con la vida en la frontera. Comenta que es algo que no había pensado mucho. Su proximidad con la frontera no les causa problemas, tienen buenas relaciones con guatemaltecos, con quienes comparten historia. Recuerda que cuando se asentaron en el lugar no sabían que estaban tan cerca de Guatemala. Caminaban por los bosques. Todo era nuevo. No había nada. "Un día íbamos caminando y nos encontramos de frente con una persona que no conocíamos; nos asustamos; él también, pero nos dimos cuenta de que había más gente, pero que ahí ya era otro país». Se percataron entonces de la existencia de pueblos del otro lado. Así fue como se conocieron y empezaron a relacionarse, visitándose y averiguando lo que había. Los guatemaltecos, siguiendo su tradición comerciante, llegaron a vender sus productos a Boca Chajul y otras poblaciones cercanas. Los habitantes de estos poblados visitaban a los guatemaltecos para asistir a fiestas o de compras. Ahora Felipe ya sabe que los habitantes de las comunidades guatemaltecas colindantes no son originarios de esos territorios, sino que fueron llevados de otras zonas de Guatemala para 
poblar la frontera. En ese sentido los habitantes de ambos lados tienen historias de vida parecidas.

Otra etapa que recuerda es la época de las guerrillas: «aquí en este lugar hubo un campamento de refugiados [...] muchos guerrilleros se escondían de este lado y nos hacíamos amigos». La gente de estos lugares simpatizaba con ellos y veían al ejército guatemalteco como el enemigo. Este lugar tuvo una casa de la guerrilla y también un campamento de refugiados que posteriormente fueron reubicados con el apoyo de la COMAR. En esa misma época — recuerda- «el ejército guatemalteco invadió el lugar y nos atacó considerándonos guerrilleros, esto fue muy peligroso, porque además invadieron suelos mexicanos». Felipe evoca todos estos recuerdos bajo el tema de la frontera, que nosotros le expusimos. Ese eje lo orilló a pensar mucho sus respuestas, «poco he pensado que vivimos en la frontera» —comentó.

Con respecto a las relaciones actuales con los pueblos guatemaltecos, comentó que tienen muchas, incluyendo las comerciales; por eso les preocupa el tipo de cambio; que el peso mexicano se ha devaluado con respecto al quetzal y es caro comprar en Guatemala; sin embargo, siguen haciéndolo por la cercanía y porque asegura que los productos son de mejor calidad. Compran medicinas, fertilizantes y herbicidas —algunos de los cuales están prohibidos en México-. Finaliza diciendo: "hay una muy buena relación con Guatemala, la gente va y viene porque hay acuerdos entre la población; así pues, aquí no hay una frontera que importe».

Al continuar el trayecto llegamos a Quiringuicharo, municipio de Marqués de Comillas. Este pueblo fue construido por gente originaria de Tabasco, según nos narra el señor Primitivo: "Yo soy tabasqueño y muchos de los que viven aquí también, pero han llegado también de Guerrero y esos son los malos; en este lugar hay violencia, hay gente mala que anda metida en problemas». En estos parajes de la selva hay una diferenciación clara de la población, dependiendo de su origen. A pregunta expresa sobre la vida ahí, don Primitivo consideró que el problema no es la frontera ni la gente de Guatemala: «la gente que viene de Guatemala, viene a trabajar en el hule y las plantaciones de palma, pero a veces se infiltra gente mala con esos que vienen a trabajar y ya aprenden qué hay aquí y arman pandillas que roban ganado».

Al igual que en otras poblaciones cercanas, las personas frecuentan los poblados de Guatemala, mantienen relaciones comerciales constantes, y el tipo de cambio nuevamente aparece como el gran problema. Don Primitivo dice que 
una buena parte de sus productos del campo los venden a Guatemala, a través de comercio informal.

Reforma Agraria, municipio de Marqués de Comillas, está retirado de la zona fronteriza. El río Lacantún es una vía de comunicación antigua y muy importante. Los recuerdos de la gente que llegó a poblar el lugar demuestran lo vieja que es la relación comercial con guatemaltecos. La señora Irma, entrevistada, evoca:

Mi marido y yo fuimos de las primeras familias que llegamos a poblar el lugar, todo era bosque, mi esposo tuvo que tirarlos para construir las primeras casas, ellos abrieron brecha, nosotros veníamos de Ayotzintepec, Oaxaca. Mi marido había tenido un problema con la ley en el pueblo y se vino huyendo, así nos enteramos de este proyecto de abrir brecha y viajamos por autobús y por río la última parte, en el camino nació uno de mis hijos, solo nos detuvimos unos días y continuamos con el recorrido en un tronco de árbol, que lo hicieron como lancha, hasta llegar aquí.

En este ejido se ubica el más importante centro ecoturístico de Chiapas, «Las Guacamayas». Por lo tanto, siempre hay presencia de turistas nacionales e internacionales. En el poblado se habla todavía chinanteco. Cruzan la frontera para visitar a familiares, pero siempre vuelven. Irma nos cuenta: «Aquí se hablan muchas lenguas indígenas y si para nosotros Guatemala es muy cerca, a ellos son a los primeros que conocimos cuando llegamos aquí, ahí en el río venían en sus cayucos, nos ofrecían productos como jabón y azúcar».

Recuerda que había días específicos en que pasaban por el río a ofrecerles mercancías. Y ahora siguen comprándoles algunas, pero las formas han cambiado, hay más vías de comunicación, la continua convivencia con los territorios y las personas de Guatemala no les permite mirarlos como extraños.

Continuando el recorrido, por Nueva Orizaba, nos encontramos con la señora Meche. Fue interesante platicar con ella, porque su idea de la frontera es muy diferente a la de la mayoría de los otros entrevistados. Habla de violencia y desprecio; asegura que tiene muy malas experiencias con «ellos», los guatemaltecos, pero sobre todo se queja de que hay gente en su propio ejido que ha llegado de Guerrero y «es mala». Cuenta su experiencia de habitar el lugar como muy violenta y desagradable. Es originaria de la frontera Chiapas-Tabasco, concretamente de Salto de Agua. Su marido era de Paraíso, Tabasco. Se fueron buscando tierras para establecerse: «abrimos brecha, avanzábamos atrás de la máquina, aquí había muchos animales salvajes, todo era muy desagradable». Manifiesta gran inconformidad por su vida en el lugar. Ve a los guatemaltecos como «aje- 
nos». Considera que el Estado debe estar ahí ordenando la frontera «porque allá hay muchos guerrilleros que llegaban en los años de la guerra para acá». Confunde a guerrilleros con el ejército guatemalteco, pues los habitantes de esta zona aseguran que fue el ejército guatemalteco el que incursionó en estas tierras de manera violenta.

Para ella todo lo de Guatemala es malo. Nos enseñó una fotografía en la que explicaba que su marido hizo acuerdos con autoridades de Guatemala para que pudieran vivir sin problemas e intercambiar mercancías; así se respetan de ambos lados y pueden ir y venir. Ese hecho contradice sus argumentos y resentimientos hacia los guatemaltecos, pero la situación se aclara cuando manifiesta su coraje porque una hija suya se casó son un guatemalteco.

La tercera parte del recorrido continuó por el Soconusco, el otro extremo de la franja fronteriza. La primera ciudad visitada fue Tapachula, región productiva por excelencia en la que aún existen algunas de las fincas que dieron origen a las actividades agrícolas empresariales y de exportación en el área. La mayoría ahora ofrecen el servicio de turismo, pero hay productores de plátano, café y cacao que absorben grandes cantidades de trabajadores tanto locales como guatemaltecos.

Entrevistamos a empresarios, trabajadores de la salud y la educación con el objetivo de conocer la percepción que tiene la gente local sobre la frontera y sobre los centroamericanos.

Michel, joven empresaria, manifestó una visión de una ciudad próspera, en la que «siempre hay trabajo». En Tapachula hay «mucha oferta de trabajo, pero no quieren trabajar, ese es el problema». Magda —una mujer madura- dice que hay una fuerte depresión económica. Ambas entrevistadas expresan visiones encontradas también con respecto a los trabajadores guatemaltecos. Michel decía que son muy inestables, que van y vienen sin mayor compromiso y Magda consideraba que son buenos y duran mucho en un solo trabajo. Para Michel, los guatemaltecos que le interesan son sus clientes. El servicio que ofrece -entrenamiento y cuidado de perros- es para personas con recursos económicos, por lo que se beneficia de la cercanía con Guatemala. Magda considera que el problema económico que vive Tapachula se debe a que han decaído las fincas y el comercio local, esto porque los grandes centros comerciales han desplazado a los comerciantes locales y eso ha afectado a toda la economía.

Las dos coincidieron en que las grandes cadenas comerciales (Walmart y Liverpool) son el atractivo para los guatemaltecos. En los estacionamientos de 
esas tiendas es visible la cantidad de automóviles con placas de Guatemala que compran grandes cantidades de productos, que anteriormente eran adquiridos en el comercio local. Pero también el tipo de cambio ha invertido las relaciones comerciales. Actualmente los mexicanos ya no van de compras a Guatemala, porque ya no encuentran ahí precios más bajos.

Magda habla de la falta de trabajo profesional. Considera que la economía local se cayó porque no hay trabajo para los jóvenes que han estudiado, así que no pueden regresar y las empresas familiares tampoco son la opción: «solo hay que ver el Centro de la ciudad -indica_, para darse cuenta de como muchos centros comerciales están cerrados y abandonados». Michel sostiene que hay mucho trabajo porque piensa en el que ofrecen las microempresas y los pequeños comerciantes, es decir, empleos poco remunerados.

Magda proviene de una familia europea. La finca es su aspiración más importante. Sueña con los tiempos en que esa diferenciación social era tangible. Recuerda cuando iban a los bailes a Guatemala.

Michel es joven y no tiene esos recuerdos, por lo que no aspira a esa vida.

Para Magda Guatemala, la capital, es la ciudad más cercana a su vida; de hecho, afirma que el servicio médico es muy bueno: "es más fácil ir a Guatemala que a la Ciudad de México y la medicina es mucho mejor».

Para Michel, Guatemala la capital es un buen punto de negocio, pero la Ciudad de México es su referencia de ciudad cercana.

Con respecto a las trabajadoras domésticas de Guatemala, dijo Michel:

Ya no son como antes ya no se dejan que uno las regañe, se sientan en la mesa, y como ahora tienen el celular, ahí se comunican y se dan cuenta de lo que pasa en el mundo, y si van al Sam's se dan cuenta de los precios y entonces ya no se dejan, por eso ya no las llevamos al centro comercial, porque se dan cuenta del tipo de cambio y ya dejan de trabajar.

Michel, considera que las hondureñas y las salvadoreñas son mal vistas porque normalmente trabajan en los prostíbulos y van de paso, y las guatemaltecas son preferidas a pesar de todo lo dicho con anterioridad.

Magda no tenía muchas referencias sobre estos temas. Insistía en que las muchachas guatemaltecas son muy buenas trabajadoras y dada la cercanía van y vienen sin mayores problemas. Nos habló de su actividad como asesora y trabajadora de un centro de apoyo a niños tanto locales como migrantes. En cuanto a 
inseguridad, las dos consideran que la hay como en todos lados, pero no es por ser zona fronteriza

Sobre el tema de salud, nos interesó saber qué complicaciones tienen los hospitales en estas zonas que atienden constantemente a migrantes. Entrevistamos a dos médicas que trabajan en el sector público para conocer su percepción sobre la frontera y la salud.

Una de ellas es originaria de la Ciudad de México y vive en Tapachula desde hace tres años. Se casó con un médico de Comitán, y por ello se vino a Tapachula a trabajar en el Instituto Mexicano del Seguro Social (IMSS). Su percepción es que su lugar de trabajo es muy bueno y ofrece un gran servicio. Es un centro creado hace poco tiempo en Tapachula para atender a niños con cáncer. Asevera que los problemas de salud en niños, que es su especialidad, son iguales que en otras partes de México. El cáncer que registra mayor incidencia es la leucemia, «como en todo el país» —afirmó.

Aseguró que al llegar a Tapachula con un trabajo seguro y donde es más barato todo, subió su nivel de vida, pero no está satisfecha en el lugar, su percepción es que Tapachula es muy insegura, incluso más que la Ciudad de México.

Su visión sobre los problemas de salud es limitada, dado que atiende a pacientes afiliados al IMSS. Ella no tiene idea de la migración; a los migrantes, dijo, los atienden en el hospital regional. Siente inseguridad, pero no por la frontera o por los migrantes, "dicen que ellos solo están en ciertos lugares y que van de paso».

Un aspecto de vivir en Tapachula que la tiene impresionada es que se pueda tener una «muchacha» y pagarle tan barato; eso no sucede en la Ciudad de México. El hecho de que sean guatemaltecas lo facilita — dijo. «Es que aquí hay clases sociales y en la Ciudad de México eso no se ve».

Berenice es otra médica pediatra trabajadora del hospital regional. Es hija de migrantes salvadoreños, pero radicados en Tapachula desde los años ochenta; eso le da una mirada distinta del proceso de vida local. Vivió en carne propia el ser migrante, pero asegura no haber sufrido discriminación. Estudió en la Ciudad de México hasta obtener una especialidad. Volvió a Tapachula y ocupa una plaza en el sector salud. Afirma que el problema en estos servicios es muy serio, no solo por la limitación de personal, de medicamentos o por las enfermedades que ahí atienden; tienen un elemento más, que es la exigencia de los migrantes para ser atendidos; afirma que 
una gran cantidad de pacientes que están ahí afuera pidiendo ser atendidos son migrantes, pero no cumplen con el requisito de estancia legal. Con un permiso para trabajar pueden tener derecho al seguro popular, pero muchos no hacen el trámite y exigen atención. Esto nos mete en muchos problemas, porque ¿cómo damos el servicio si no cuentan con documentos?; y si no los atendemos, nos acusan con Derechos Humanos, y ahí nos enfrentamos con otro problema muy serio. Además, no tenemos suficientes fármacos y médicos para atender todos los casos que nos llegan. Los migrantes no quieren comprar las medicinas que no tenemos y llamamos a los cónsules de Guatemala o El Salvador y no apoyan a sus connacionales ni siquiera cuando alguien muere. Llamamos a las organizaciones que apoyan a migrantes para que los ayuden, pero siempre es muy complicado conseguir apoyo para tantas personas.

La trabajadora social tiene que lidiar con estos problemas. Nos cuenta que gran parte de su trabajo es buscar ayuda para estos migrantes, sobre todo cuando los pacientes son niños: "Ahora mismo tenemos casos de niños con dengue hemorrágico y ya no caben en la sala de urgencias», no tiene papeles, no tienen dinero, los cónsules no apoyan. ¿Qué hacemos?, recurrir a las organizaciones de apoyo a migrantes, que a veces pueden ayudar y a veces ya no.

Solo para tener alguna idea en el tema de educación entrevistamos a un profesor de educación especial que labora en Ciudad Hidalgo y nos comentó que desde su percepción y conocimiento sobre el tema, México tiene mejor nivel educativo que Guatemala, porque ofrece más servicios e invierte mayores recursos públicos para ellos. Nos comenta que el tema de la frontera para él y sus colegas, tanto mexicanos como guatemaltecos, sí ha sido tema de discusión; saben que no pueden influir en las políticas nacionales para tener una mirada integral del problema en la región fronteriza, pero que existen varios acuerdos entre autoridades locales y maestros de ambos países para que los niños de la franja fronteriza puedan recibir educación en México, sin importar sin son guatemaltecos. Nos cuenta de su propia experiencia. Él es especialista en educación especial, y tiene alumnos de Guatemala que requieren este tipo de servicio y llegan todos los días.

Pasan diariamente hacia México para recibir clases, porque allá no cuentan con el sistema. Este tipo de acuerdos es común entre localidades de la franja fronteriza, pero son acuerdos locales; sus autoridades los apoyan para que puedan venir sin problemas y las nuestras también, así que aquí para nosotros no hay fronteras. 
Para finalizar el recorrido entrevistamos a un agente de una empresa centroamericana con presencia en Tapachula. Es de destacar la gran cantidad de relaciones comerciales fronterizas que existen. Hay varias empresas centroamericanas en las que participan mexicanos y ven a Tapachula como un continuo productivo y comercial de Centroamérica. Tienen identificado el territorio con problemáticas y negocios similares desde Costa Rica. Ello se da de manera histórica y natural, porque comparten cultivos como café, plátano y cacao; por lo tanto, comparten problemas parecidos, además de toda una trayectoria histórica de convivencia y acuerdos.

\section{Reflexiones finales}

Lo relatado da una idea sobre lo complejo que resulta hacer investigación colectiva, pero también remarca las ventajas de ello; las discusiones siempre llevan a mayores reflexiones y a la posibilidad de construir resultados más complejos. El trabajo de campo con varias miradas siempre abonará a abarcar más temas. Los primeros resultados aquí señalados nos permiten tener una idea muy general sobre la complejidad de la franja fronteriza y también algunos elementos de las diversas percepciones que hay sobre la frontera, por lo que es evidente que hablar de la frontera Chiapas-Guatemala requiere profundizar en la heterogeneidad del territorio sin perder de vista la inmensa diversidad cultural, histórica y de vida y dejar en claro que las formas en que destacan los resultados está íntimamente relacionadas con los intereses y disciplinas de los investigadores.

\section{Bibliografía básica}

Centro de Estudios Indígenas, 1987, Anuario II, México, Universidad Autónoma de Chiapas.

Contreras Suárez, Enrique, 1998, La mazorca de la discordia, Informe final, proyecto PAPIIT-DGAPA-IN 303294, México, Universidad Nacional Autónoma de México.

Fábregas Puig, Andrés, Juan Pohlenz, Mariano Báez y Gabriel Macías, 1985, La formación histórica de la Frontera Sur, México, Centro de Investigaciones y Estudios Superiores en Antropología Social-Sureste (Cuadernos de la Casa Chata, 124).

Fábregas Puig, Andrés, 2015, Marcos Institucionales de la Antropología en Chiapas a finales del segundo milenio, Tuxtla Gutiérrez, Centro de Estudios Superiores de México y Centroamérica-Universidad de Ciencias y Artes de Chiapas.

Geertz, Clifford, 2003, La interpretación de las culturas, 12a. ed., Barcelona, Gedisa. 
Jimeno, Myriam, 2016, «Introducción el enfoque narrativo», en Myriam Jimeno, et al. (eds.), Etnografías contemporáneas III: las narrativas en la investigación antropológica, Bogotá, Universidad Nacional de Colombia.

Visacovsky, Sergio, 2016, Lo narrativo y la investigación antropológica sobre la producción de historias, en Pabón Myriam, Carolina Pabón, Daniel Varela e Ingrid Diaz (eds.), Etnografías contemporáneas III: las narrativas en la investigación antropológica, Bogotá, Universidad Nacional de Colombia.

\section{Cómo citar:}

Camacho Velázquez, Dolores, 2019, «La franja fronteriza Chiapas-Guatemala. Notas de campo», Revista Pueblos y fronteras digital, volumen 14, e-455. doi.org/10.22201/ cimsur.18704115e.2019.v14.455 